\title{
Combining Ability in Diploid and Triploid Sugarbeet Hybrids From Diverse Parents*
}

\author{
J. M. Lasa ${ }^{1}$, I. Romagosa ${ }^{2}$, R. J. Hecker ${ }^{3}$, and J. M. Sanz ${ }^{1}$ \\ ${ }^{1}$ Aula Dei Exp. Stn., Zaragoza, Spain; ${ }^{2}$ Politechnic University of \\ Catalunya, Spain; and ' ${ }^{3}$ SDAA-ARS, Fort Collins, CO 80523.
}

\begin{abstract}
An international cooperative project to develop monogerm sugarbeet (Beta vulgaris L.) hybrids for use in Spain, and potentially in the U.S., involved the development of sugarbeet hybrids between diploid U.S. cytoplasmic male sterile (CMS) monogerm lines and diploid and tetraploid European pollinators. A fixed set of $\mathbf{1 2 0}$ hybrids involving $\mathbf{3 2}$ female lines and $\mathbf{1 5}$ pollinators were evaluated over six environments. General (GCA) and specific (SCA) combining ability estimates were derived independently for diploid and triploid hybrids. There was a masking effect by tetraploid pollinators on diploid CMS lines. The relative importance of the pollinator vs. the female lines was different in diploid than in triploid hybrids. No significant female GCAs were detected for the triploid hybrids, whereas, GCA estimates for the same CMS lines in diploid hybrids were generally significant. Higher environmental stability was detected among triploid than among diploid hybrids. The use of public monogerm CMS lines crossed to open-pollinated pollinators was found to be an acceptable way to readily start a . monogerm sugarbeet hybrid breeding program.
\end{abstract}

Additional index words: Beta vulgaris, breeding, cultivars.

M ost commercial sugarbeet (Beta vulgaris L.) cultivars currently grown in Europe and the U.S. are either diploid $(2 n=2 x=18)$ or triploid $(2 n=3 x=27)$ monogerm hybrids. They are produced by crossing a cytoplasmic male sterile (CMS) monogerm inbred or $F_{1}$ with a diploid or tetraploid multigerm pollinator. Most cultivars developed in the United States are diploid, whereas, both diploid and triploid hybrids are being developed in Europe.

* Joint contribution of the Aula Dei Exp. Stn., Zaragoza, Spain, and the U.S. Dept. of Agriculture, Agricultural Research Service. Supported in part by the U.S.-Spain Program of Cooperation in Science and Technology, Project IIIP3040. 
Hybrid vigor for root yield was first reported more than 40 years ago $(3,20)$. Capitalization on this expression of heterosis became possible after the discovery, description, and distribution of CMS and its non-restorer genotypes by Owen (12) in 1945. Since then, and especially after the discovery of monogerm in the U.S. by Savitsky (15) in 1950, significant effort has been devoted to combining ability assessment methods and identification of high combining genotypes $(6,8,9,13,14)$.

The components of recoverable sucrose yield in sugarbeet are root yield, sucrose content, and purity (ratio of sucrose to total soluble solids). In unselected diploid populations, Smith and Hecker (17) reported that root yield was clearly the most important yield component. However, root yield and sucrose content were similar in importance when considering improved populations. Partition of genetic variances and estimates of gene action for root yield, sucrose content, and quality components $(5,11,18)$ have shown nonadditive gene action to be most important for root yield, but additive gene action to be most important for sucrose content and quality components. General and specific combining ability (GCA and SCA) estimates developed from a diploid five-variety diallel (8) showed GCA to be more important than SCA for both root yield and sucrose content. However, Smith et al. (18) reported a larger SCA component for root yield in a diallel cross of eight inbred parents.

An assessment of combining ability of triploid hybrids by Helmerick et al. (9) showed a significant SCA component for yield in only two of three locations. Only triploid hybrids were included in the experiment.

The current interaction of European and U.S. sugarbeet variety developers undoubtedly has involved extensive hybridizations among diploid and tetraploid breeding lines from both areas. However, these private research efforts have not been reported.

The objective of this study was to assess and compare the combining ability of sugarbeet hybrids among U.S. diploid monogerm CMS publicly released lines and diploid and tetraploid European pollinators that were developed in Spain from multigerm open-pollinated varieties and breeding lines. A secondary objective was to draw inferences about the stability of these hybrids and about the value of this approach to rapidly get into a program for breeding monogerm sugarbeet hybrids.

\section{MATERIALS AND METHODS}

Fifteen European pollinators and 32 U.S. CMS monogerm lines were used for the production of experimental hybrids. The pollinators were developed in Spain from open-pollinated diverse European populations. They were selected for at least two cycles of phenotypic mass selection for sucrose content and root mor- 
phology, followed by two cycles of selection for GCA, using a polycross progeny test and a diploid red sugarbeet top-cross tester, respectively. Eight of the pollinators were tetraploids that had been developed from tetraploid populations that originated from Sweden (three), Germany, Denmark, Poland, Holland, and Spain. Seven pollinators were diploids that had been developed from open-pollinated sugarbeet populations that originated from Poland (three), Denmark (two), Germany, and Sweden.

Thirty-two CMS public monogerm lines developed by the Agricultural Research Service, U.S. Department of Agriculture were used. They were selected so that they represented a diverse sample of monogerm sugarbeet genotypes.

Of the 480 possible hybrids, seed of 358 hybrids was produced in 1980 in Spain in sufficient quantities for yield testing. Of these 358 hybrids, 120 were chosen for testing and for developing GCA estimates used in the screening of potential parents. These 120 hybrids were chosen to represent the entire array of parental genotypes because they had the potential of being adapted to Spanish sugarbeet production regions. The genetic mating design was an incomplete factorial, or North Carolina II design.

The hybrids were evaluated at six locations in Spain. Four in the northern part were sown in the spring of 1981 and two were planted in the fall of 1981 in southern Spain under nonirrigated conditions. The experimental design was a double $8 \times 8$ triple lattice including eight checks. Multiple row plots, standard cultural practices, and tare lab sucrose analyses were used at all locations.

The data for root yield, sucrose content, and gross sucrose yield were analyzed independently for each ploidy level in order to detect any differential behavior of diploid and triploid hybrids.

The six Spanish locations were grouped using randomized complete block designs. Bartlett's tests for homogeneity of error variances were found to be significant for most variables for both diploid and triploid hybrids. However, the ratios of the largest to the smallest error variances were small, usually less than 3 . Although some of these variance ratios were statistically significant, there were more than 150 degrees of freedom associated with the error term in each location analysis which made the rather small ratios significant. Hence, the data were pooled across locations, recognizing that the heterogeneity was small relative to other components. The pooled coefficients of variation, although a little high, were found to be acceptable for a combined analysis of variance ( $14 \%$ for root yield and $4 \%$ for sucrose content). Locations were treated as random effects while hybrids were regarded as fixed. To estimate GCA and SCA effects, the hybrids sums of squares were partitioned into three sources of variation, pollinator GCA, female GCA, and the residual, which was considered an adequate estimate of pollinator $x$ female line 
interaction, i.e., SCA effects. The hybrid $x$ location interaction also was partitioned in a similar way.

In order to compare the relative importance of GCA and SCA estimates for the variables studied among diploid and triploid hybrids, variance components were estimated on a random model assumption. Although this assumption may hold true with certain restrictions to the set of CMS monogerm lines used, it probably should not be accepted for the fixed set of pollinators used. For this reason, generalized conclusions should not be applied to materials beyond this study.

Simple correlation coefficients were calculated for the GCA deviations of the CMS lines estimated independently from diploid and triploid hybrids.

\section{RESULTS}

The mean root yield was $9 \%$ higher for the triploid than for the diploid hybrids (Table 1); the sucrose content was the same for both ploidy levels.

Analyses of variance (Table 2) showed significant differences among diploid hybrids and among triploid hybrids for all three variables. The hybrid $x$ location interaction was also significant in all cases except for sucrose in the triploids. The partition of the hybrids sums of squares showed that the pollinator and the female GCAs were different in diploid than in triploid hybrids. In the triploid hybrids the pollinator effects were highly significant for the three variables, but the female effects were not significant. However, the female effects were found to be significant among the diploid hybrids.

To assess the relative importance of GCA, SCA, GCA $x$ location, and SCA $x$ location effects and interactions, their components of variance were estimated under the random model assumption. In general, the diploid genotypic $(\mathrm{H})$ components (Table 3 ) were smaller than those of the genotype $(\mathrm{H}) \times$ environment $(\mathrm{L})$ interaction; this indicates a need for diverse testing environments before a good assessment of the commercial value of the diploid hybrids can be made. However, the magnitude of the genotypic components of variance for the triploid hybrids was approximately twice

Table 1. Means and standard errors for root yield, sucrose content, and gross sucrose yield for 56 diploid and 64 triploid sugarbeet hybrids combined from six locations.

\begin{tabular}{lccc}
\hline Hybrids & $\begin{array}{c}\text { Root yield } \\
\text { Mg ha-1 }\end{array}$ & Sucrose content \% & $\begin{array}{c}\text { Gross sucrose yield } \\
\mathbf{M g ~ h a}^{-1}\end{array}$ \\
\hline $\begin{array}{l}\text { Diploids } \\
\text { Triploids }\end{array}$ & $51.0 \pm 0.95 \mathrm{a}^{*}$ & $16.9 \pm 0.09 \mathrm{a}$ & $8.7 \pm 0.15 \mathrm{a}$ \\
\hline
\end{tabular}

- Means followed by different letters within columns differ significantly at 0.05 probability level. 
Table 2. Mean squares for root yield, sucrose content, and gross sucrose yield for 56 diploid and 64 triploid sugarbeet hybrids combined from six locations.

\begin{tabular}{|c|c|c|c|c|c|c|c|c|}
\hline \multirow{2}{*}{ Source } & \multicolumn{2}{|c|}{ df } & \multicolumn{2}{|c|}{$\begin{array}{c}\text { Root yield } \\
\text { Mg ha' }^{-1}\end{array}$} & \multicolumn{2}{|c|}{$\begin{array}{c}\text { Sucrose } \\
\text { content \% }\end{array}$} & \multicolumn{2}{|c|}{$\begin{array}{c}\text { Gross sucrose yield } \\
\mathrm{Mg} \mathrm{ha}^{-1}\end{array}$} \\
\hline & $2 x$ & $3 x$ & Diploids & Triploids & Diploids & Triploids & Diploids & Triploids \\
\hline Hybrids & 55 & 63 & $158^{* *}$ & $399 *$ & $3.5^{* *}$ & $4.3 * *$ & $3.4^{*}$ & $6.9 *$ \\
\hline $\begin{array}{l}\text { Female GCA } \\
\text { Pollinator GCA } \\
\text { Residual (SCA) }\end{array}$ & $\begin{array}{r}26 \\
6 \\
23\end{array}$ & $\begin{array}{r}28 \\
7 \\
28\end{array}$ & $\begin{array}{l}251^{* *} \\
143 \\
56\end{array}$ & $\begin{array}{r}128 \\
1560 * * \\
379 * *\end{array}$ & $\begin{array}{l}3.4 * * \\
9.7 * * \\
2.1 * *\end{array}$ & $\begin{array}{r}0.9 \\
22.3 * * \\
3.2 *\end{array}$ & $\begin{array}{l}5.2^{*} \\
4.5 \\
1.0\end{array}$ & $\begin{array}{r}3.5 \\
21.3 * * \\
6.6^{* *}\end{array}$ \\
\hline $\begin{array}{r}\text { Hybrids } x \\
\text { Location }\end{array}$ & 2753 & 315 & $72 *$ & $89 *$ & $0.7^{* *}$ & 0.8 & $2.2 * *$ & $2.0 *$ \\
\hline $\begin{array}{l}\text { Female GCA } \\
\times \text { Loc } \\
\text { Pollinator GCA }\end{array}$ & 1301 & 140 & $94 *$ & 140 & $0.7 *$ & 0.6 & $2.8 *$ & $2.3 *$ \\
\hline $\begin{array}{l}\times \text { Loc } \\
\text { Residual } \\
(\text { SCA } \times \text { Loc })\end{array}$ & $\begin{array}{r}30 \\
1151\end{array}$ & $\begin{array}{r}35 \\
140\end{array}$ & $\begin{array}{l}77 * \\
47\end{array}$ & $\begin{array}{l}113^{* *} \\
81^{*}\end{array}$ & $\begin{array}{l}1.0 * * \\
0.6 * *\end{array}$ & $\begin{array}{l}1.8^{* *} \\
0.8 *\end{array}$ & $\begin{array}{l}2.5 * * \\
1.3\end{array}$ & $\begin{array}{l}2.4^{*} \\
1.5\end{array}$ \\
\hline $\begin{array}{l}\text { Intrablock } \\
\text { error }\end{array}$ & 6607 & & 51 & 64 & 0.4 & 0.5 & 1.3 & 1.6 \\
\hline
\end{tabular}

$\because *$ Probability of Type 1 Error less than 0.05 and 0.01 , respectively.

Table 3. Variance components for root yield, sucrose content, and gross sucrose yield for 56 diploid and 64 triploid sugarbeet hybrids combined from six locations.

\begin{tabular}{|c|c|c|c|c|c|c|}
\hline \multirow[t]{2}{*}{ Statistics ${ }^{+}$} & \multicolumn{2}{|c|}{ Root yield } & \multicolumn{2}{|c|}{ Sucrose content } & \multicolumn{2}{|c|}{ Gross sucrose yield } \\
\hline & Diploids & Triploids & Diploids & Triploids & Diploids & Triploids \\
\hline $\begin{array}{c}\sigma_{\mathrm{H}}^{2} \\
\sigma_{\mathrm{F}}^{2} \\
\sigma_{\mathrm{P}}^{2} \\
\sigma_{\mathrm{sca}}^{2} \\
\sigma_{\mathrm{HLL}}^{2} \\
\sigma_{\mathrm{FxL}}^{2} \\
\sigma_{\mathrm{P}}^{2} \\
\sigma_{\mathrm{sc \textrm {L }}}^{2} \\
\sigma_{\mathrm{E}}^{2}\end{array}$ & $\begin{array}{l}4.76 * \\
4.69 * \\
0.54 \\
0.33 \\
7.27 * \\
7.96 * \\
1.40 * \\
0.00 \\
50.60\end{array}$ & $\begin{array}{c}17.13 * \\
0.00 \\
8.09 * \\
16.54 * \\
8.37{ }^{* *} \\
1.89 \\
1.32 \\
5.70^{*} \\
64.30^{*}\end{array}$ & $\begin{array}{l}0.16 * \\
0.04 \\
0.06 * \\
0.08 * \\
0.09 * \\
0.02 \\
0.02 * \\
0.06 * \\
0.42\end{array}$ & $\begin{array}{l}0.19 * \\
0.00 \\
0.12 * * \\
0.15 * * \\
0.11 * \\
0.00 \\
0.04 * \\
0.09 * \\
0.49\end{array}$ & $\begin{array}{l}0.06 * \\
0.09 * * \\
0.02 \\
0.00 \\
0.30 * * \\
0.25 * * \\
0.05 * \\
0.06 \\
1.32\end{array}$ & $\begin{array}{l}0.27 * * \\
0.00 \\
0.10 * \\
0.28 * * \\
0.11 * * \\
0.12 * * \\
0.03 \\
0.00 \\
1.63\end{array}$ \\
\hline
\end{tabular}

$\because \cdots$ Probability of Type I Error less than 0.05 and 0.01 , respectively.

$\cdot \mathrm{H}=$ Hybrids, $\mathrm{F}=$ Female GCA, $\mathrm{P}=$ Pollinator $\mathrm{GCA}, \mathrm{L}=$ Locations, $\mathrm{E}=$ Intrablock Error.

the value of the genotype $x$ environment interaction. This suggests that the triploid hybrids were more stable over a series of environments than were the diploids.

The female GCA variance components $(F)$ for root yield and gross sucrose yield (Table 3 ) were more important than those of pollinator GCAs for diploid hybrids. SCA variance components and SCA $\times$ location interactions were not significant for root yield and gross sucrose of the diploid hybrids; whereas, significant SCA 
Table 4. Correlation among female GCA estimates from diploid and triploid sugarbeet hybrids. ${ }^{+}$

\begin{tabular}{lccc}
\hline GCA estimate & Root yield & Sucrose content & Gross sucrose yield \\
\hline Root yield & 0.18 & -0.08 & $0.80^{* *}$ \\
Sucrose content & 0.02 & $0.45 *$ & 0.39 \\
Gross sucrose yield & $0.92 * *$ & 0.31 & 0.18 \\
\hline
\end{tabular}

** Probability of Type I Error less than 0.05 and 0.01 , respectively.

- Values on the main diagonal are correlation coefficients among female GCA estimates independently derived from diploid and triploid hybrids. Values above the main diagonal are correlation coefficients among GCA estimates derived from diploid hybrids. Values below the main diagonal are correlation coefficients among GCA estimates derived from triploid hybrids.

components were found among the same materials for sucrose content. Among triploid hybrids the SCA effects and the SCA x location interactions, except for gross sucrose, were both significant.

Correlation analysis was used to compare GCA deviations for the 32 CMS lines (Table 4). No significant correlation was detected $(r=0.18)$ between female GCA estimates for root yield calculated independently from diploid and triploid hybrids; the best females for high root yield diploid hybrids were not necessarily the best females for triploid crosses. However, a statistically significant positive correlation was detected among GCA estimates for sucrose content $(r=0.45)$, suggesting that the same females tended to contribute high sucrose to both diploid and triploid hybrids.

Correlation coefficients for estimates of female GCA components within a given ploidy level are also shown in Table 4 . They do not correspond exactly to those values estimated directly from the hybrids, i.e., no significant negative correlation between GCA for root yield and sucrose content was detected for this set of CMS lines, which could be due to the small nonsignificant differences in sucrose content among them (Table 2). The correlation coefficients of both root yield and sucrose content GCA estimates with gross sucrose yield GCA were nearly the same for both ploidy levels (0.92 for triploids and 0.80 for diploids).

\section{DISCUSSION}

The set of 32 CMS diploid lines and 15 pollinators (seven diploid and eight tetraploid) used as parents to generate the hybrids in this study were considered to be a fixed set. The 120 hybrids included in this study were also a fixed set since their inclusion was a decision based on (a) need to have some hybrids of each ploidy level for each female parent, (b) desirable combination of parents for disease resistance, bolting resistance, and potential adaptation, and (c) previous experience with some of the parents. 
There was significant root yield advantage of the average triploid hybrid (Table 1). The gross sucrose yield was significantly higher for the mean of the triploid hybrids than for the diploids. Although no juice purity was determined, the net sugar yield advantage of the triploids probably should be reduced, since it has been reported that polyploids have more nonsucrose soluble solids than diploids (19).

Parental influence of CMS lines on hybrids was higher when diploid pollinators were used than when triploid hybrids were developed using tetraploid pollinators. The contribution of tetraploid pollinators to the final yield of triploid hybrids was quantitatively more important than that of the diploid CMS lines (Tables 2 and 3). The fact that significant differences were found among the same set of CMS lines when crossed to diploid pollinators but not when crossed with tetraploids suggests that a certain degree of dosage effect existed in triploid hybrids. We do not believe that this is explained solely by the differences between diploid and tetraploid pollinator because, although undoubtedly genetically different, they were derived from productively equivalent populations derived by the same selection procedures.

The masking effect of tetraploid pollinators of diploid CMS lines found in triploid hybrids may explain partially the significant differences for both yield and quality components that have been detected among certain reciprocal sugarbeet triploids $(2,4,7,19)$. It also has been proposed that such differences are due to the relative frequencies of aneuploid seed on $2 \times X 4 x$ vs. $4 \times X 2 \times$ crosses (1), and to the $4: 3$ vs. 2:3 ploidy ratio of perisperm to embryo (2). Although these hypotheses may provide an explanation for yield and sucrose differences found among equivalent reciprocal $4 \times \times 2 \times$ vs. $2 \times \times 4 \times$ crosses, they are not plausible explanations for the differences observed between nonequivalent $2 \times \times 2 x$ and $2 \times X 4 x$ crosses.

The types of gene action suggested by the relative importance of root yield and gross sucrose yield GCA and SCA estimates for the diploid hybrids (Table 3 ) are in contrast to what generally has been reported. This could be due to the specific nature of the diploid materials used. On the other hand, significant levels of heterosis, shown by the statistical significance of the SCA effects, were found among triploid hybrids for all three variables studied. However, as we would have expected, the SCA effects were relatively more important for root and gross sucrose yield than for sucrose content (Table 3).

The nonsignificant correlation between root yield GCA deviations estimated independently from diploid and triploid hybrids could again be due to differences among the diploid and tetraploid pollinators used, together with the related fact that nonadditive gene action controlling this character was detected for the triploid hybrids. However, as mentioned before, it is not likely that genotypic differences among diploid and tetraploid 
pollinators specific to this experiment could account for this differential behavior of CMS lines in diploid and triploid hybrids. This should be taken into account when prediction methods based on GCA (16) are to be used in the simultaneous production of both diploid and triploid hybrids.

The use of monogerm CMS lines crossed to open-pollinated pollinators was found to be an acceptable way to readily start a monogerm sugarbeet hybrid breeding program. A few of the experimental hybrids that significantly outyielded commercial checks showed potential value for commercial use (data not shown). The diversity of the germplasm used, CMS lines developed in the U.S., and pollinators selected from within European open-pollinated populations may have contributed to the yield increases.

\section{LITERATURE CITED}

1. Bosemark, N. O. 1967. The effect of aneuploidy on yield of anisoploid sugar beet varieties. J. Int. Inst. Sugar Beet Res. 2:145-161.

2. Bosemark, N. O. 1977. Use of tetraploid monogerm male-steriles in triploid hybrid-seed production. Proc. Int. Inst. Sugar Beet Res. 271-287.

3. Doxtator, C. W. and A. W. Skuderna. 1942. Some crossing experiments with sugar beets. Proc. Amer. Soc. Sugar Beet Technol. 3:325-335.

4. Fitzgerald, P. 1977. Influence of crossing direction on the agronomic performance of sugar beet triploids. Irish J. Agr. Res. 16:149-153.

5. Hecker, R. J. 1967. Evaluation of three sugarbeet breeding methods. J. Amer. Soc. Sugar Beet Technol. 14:309-318.

6. Hecker, R. J. 1985. Reciprocal recurrent selection for the development of improved sugarbeet hybrids. J. Amer. Soc. Sugar Beet Technol. 23:47-58.

7. Hecker, R. J., R. E. Stafford, R. H. Helmerick, and G. W. Maag. 1970. Comparison of the same sugarbeet $F_{1}$ hybrids as diploids, triploids, and tetraploids. J. Amer. Soc. Sugar Beet Technol. 16:106-116.

8. Helmerick, R. H., R. E. Finkner, and C. W. Doxtator. 1963. Variety crosses in sugar beets (Beta vulgaris L.). I. Expression of heterosis and combining ability. J. Amer. Soc. Sugar Beet Technol. 12:573-584.

9. Helmerick, R. H., R. E. Finkner, and C. W. Doxtator. 1965. Combining ability in autotriploid sugar beets (Beta vulgaris L.). J. Amer. Soc. Sügar Beet Technol. 13:538-547.

10. Helmerick, R. H., R. E. Finkner, and C. W. Doxtator. 1965. Paired-plant crosses in sugar beets. J. Amer. Soc. Sugar Beet Technol. 13:548-554.

11. MacLachlan, J. B. 1972. Estimation of genetic parameters in a population of monogerm sugar beet (Beta vulgaris L.). 1. Sib-analysis of mother-line progenies. 2. Offspring/parent regression analysis of mother-line progenies. 3. Analysis of a diallel set of crosses among heterozygous populations. Irish J. Agr. Res. 11:237-246, :319-325, :327-338.

12. Owen, F. V. 1945. Cytoplasmically inherited male-sterility in sugar beet. J. Agr. Res. 71:423-440.

13. Oldemeyer, R. K. 1954. General combining ability of sugar beet inbreds as determined with two different top cross testers. Proc. Amer. Soc. Sugar Beet Technol. 8(2):59-63.

14. Oldemeyer, D. L. and G. E. Rush. 1960. Evaluation of combining ability in self-fertile lines of sugar beets using male-sterile testers. J. Amer. Soc. Sugar Beet Technol. 11:175-185.

15. Savitsky, V. F. 1950. Monogerm sugar beets in the United States. Proc. Amer. Soc. Sugar Beet Technol. 6:156-159. 
16. Skaracis, G. N. and G. A. Smith. 1984. Prediction of three-way top cross sugarbeet hybrid performance. Crop Sci. 24:55-60.

17. Smith, G. A. and R. J. Hecker. 1973. Components of yield of recoverable sugar in random and improved sugarbeet populations. Can. J. Plant Sci. 53:665-670.

18. Smith, G. A., R. J. Hecker, G. W. Maag, and D. W. Rasmuson. 1973. Combining ability and gene action estimates in an eight parent diallel cross of sugarbeet. Crop Sci. 13:312-316.

19. Smith, G. A., R. J. Hecker, and S. S. Martin. 1979. Effects of ploidy level on the components of sucrose yield and purity in sugarbeet. Crop Sci. 19:319-323.

20. Stewart, D., C. A. Lavis, and G. H. Coons. 1940 . Hybrid vigor in sugarbeets. J. Agr. Res. 60:715-738. 